\title{
13
}

\section{Interdisciplinary research programme in Chiapas}

\author{
Felix M. Bivens
}

\section{Context}

The Interdisciplinary Programme on Human Development was launched in 1995. Members of the Autonomous University of Mexico (UAM) Rural Development Programme had been working in the area for some years before that; however, the rise of the Zapatista movement in 1994 caused these academics to refocus their work under a human development approach 'oriented towards guaranteed human rights to the whole population' (Cortez Ruiz, 2003, p. 47). The work of the Human Development programme is structured along four axes:

- health, nutrition and quality of life;

- technology, production and environment;

- cultural processes of learning and human rights;

- social strategies, public policies and power relations.

Academically, the Human Development group works with a variety of students from undergraduate, postgraduate and professional programmes. Mexican law mandates that all university students engage in 'social service. This translates into six-month to one-year placements where students are expected to use their academic knowledge and professional skills for the common good. Many students at all levels are drawn to Chiapas because of the notoriety of the Zapatista movement. The Human Development programme provides them with an infrastructure for their social service placements; approximately 100 students per year contribute. Moreover, the programme has developed its own degree programmes. Some of these are academic degrees and others are diploma programmes designed for local development practitioners and other indigenous community leaders. This fits in with another overall goal of the programme, which is to 'create a space where people from local organizations can express their priorities and reflect upon what they are doing, what they want to do and what kind of collaborations would be desirable' (ibid., p. 48). Although the programme works to bring outside resources, knowledge and expertise into the region, these resources are directed by locally determined goals. Indeed, one of the challenges cited by academics is getting university students to recognize that the local populations have their own priorities and capabilities and that students' social service and/or research should be in alignment with these endogenous priorities. 


\section{Activities}

The primary academic course facilitated by the Human Development programme is the two-year MA in rural development. This course is aimed at mid-career professionals who already have substantial training and work experience in a particular discipline or profession. Rather than furthering skills within a particular occupational field, the course works to provide student participants 'with a firm intellectual and practical grounding on how to use grassroots, "bottom-up" community development approaches to make greater gains on the issues in which they are addressing' (Mott, 2005, p. 33) already.

The programme begins with an intensive three-month classroom experience where students read and study various facets of Mexico's rural life. They engage in discussions with academics from relevant fields such as economists and agronomists. The experience of the participants is also highly valued; much opportunity is provided for reflection and for small group work in which students bring their experiences and diverse disciplinary perspectives into the classroom to augment the academic perspectives. MA students also receive participatory action research (PAR) training and learn to incorporate participatory methods into their work generally.

As the students complete this intensive period, they choose a practicum project as the primary focus of their programme's work and research. This initial phase is the most extended period on campus and in class that MA students experience. The remainder of the programme is slanted towards fieldwork. Cyclically throughout the fieldwork, students spend four weeks in the field with their projects and one week back in class. Class time is a combination of reflecting on the ongoing field experience and progressing through a sequential set of academic modules which continue to expand the participants' practical, conceptual and methodological knowledge about rural development. However, the programme emphasizes that social change is not the product of technical knowledge or good methods; rather it is about shifting power relations and bringing communities into greater participation in political and policy debates where the radical needs of these communities can be expressed, heard and addressed systemically. As such, the course also focuses on concepts of power, power analysis, citizenship, social mobilization and collective action.

Students who stay in the programme for one year receive a diploma in rural development. Those who stay on for two years and complete a substantial report and analysis of their field project are awarded the MA degree. Some students are awarded funding to continue their research even further so that they may complete a doctorate with the Human Development programme. 